\title{
Urdimento
}

Revista de Estudos em Artes Cênicas

E-ISSN: 2358.6958

\section{pesar as palavras e estriar as hegemonias: autocuidado e fracasso em duas danças gordas}

Anderson Luiz do Carmo

Jussara Belchior Santos

\section{Para citar este artigo:}

DO CARMO, Anderson Luiz; SANTOS, Jussara Belchior. pesar as palavras e estriar as hegemonias: autocuidado e fracasso em duas danças gordas. Urdimento, Florianópolis, v. 1, n. 40, mar./abr. 2021.

do) DOI: http:/dx.doi.org/10.5965/1414573101402021e0106

Este artigo passou pelo Plagiarism Detection Software | iThenticate 
pesar as palavras e estriar as hegemonias:

autocuidado e fracasso em duas danças gordas

\author{
Anderson Luiz do Carmo \\ Jussara Belchior Santos ${ }^{2}$
}

\begin{abstract}
Resumo
O presente artigo se desencadeia a partir das propostas estéticas dos trabalhos: Peso Bruto (2017) e Ensaio sobre a retórica (2017). Para investir teórica e radicalmente na negatividade do peso, as autoras esgarçam o imperativo de leveza na sociedade de consumo contrapondo-o por meio da noção de fracasso. Assim, questiona-se a necessidade de uma cura uma vez percebido o protocolo de adoecimento que impede a gordura de ser compreendida para além da patologia, da feiura e da preguiça.
\end{abstract}

Palavras-chave: Gordura. Fracasso. Autocuidado. Dança. Dramaturgia.

weighing words and tearing up hegemonies:

self-care and failure in two fat dance pieces

\begin{abstract}
This text starts off by the aesthetic proposals of the solo pieces: Gross Weight (2017) and Essay on rhetoric (2017). In order to invest theoretically and radically in the negativity of the weight, the authors tear up the imperative of lightness in the consumer society, contrasting it through the notion of failure. Thus, the need for a cure is questioned once the protocol of illness is perceived, in which fatness is prevented from being understood beyond pathology, ugliness and laziness.
\end{abstract}

Keywords: Fatness. Failure. Self-care. Dance. Dramaturgy.

1 Artista e pesquisador das artes. Graduado na Licenciatura e Bacharelado em Teatro no CEART-UDESC Mestre em Teatro pelo PPGT-UDESC e doutorando na mesma instituição, Bolsista FAPESC. ander lc5@hotmail.com (9) http://lattes.cnpq.br/6904413725101553

(i) https://orcid.org/0000-0001-5093-6438

${ }^{2}$ Bailarina gorda. Mestre e doutorando pelo programa de Pós-Graduação em Teatro (PPGT), pelo Centro de Artes (CEART) da Universidade do Estado de Santa Catarina (UDESC).Bolsista CAPES. jusbelchior@gmail.com

http://lattes.cnpq.br/1744238603781581

https://orcid.org/0000-0002-8592-6229 
pesar las palabras y estriar las hegemonías:

cuidado de sí y fracaso en dos piezas para cuerpas gordas

\section{Resumen}

Este artículo se desarrolla a partir de las propuestas estéticas de las obras: Peso Bruto (2017) y Ensayo sobre la retórica (2017). Haciendo una apuesta teórica y radical en la negatividad del peso, las autoras rompen el imperativo de la ligereza en la sociedad de consumo, contraponiéndolo a través de la noción de fracaso. Así, se cuestiona la necesidad de una cura una vez que se percibe un protocolo de la enfermedad, que impide que se entienda la grasa más allá de la patología, la fealdad y la pereza.

Palabras clave: Grasa. Fracaso. Cuidado de sí. Danza. Dramaturgia. 
As dramaturgias dos solos em torno dos quais gravitam os debates aqui articulados serão lidas a partir de três gestos em comum que (se) investem em experiências de ordem coletiva partilhadas por corpas ${ }^{3}$ gordas, por tanto, corpas que desobedecem a imperativos de gênero e a sinonimização operada entre disciplina, beleza e magreza. Os três gestos em questão operam em instâncias banais, eróticas e oníricas da experiência gorda, pois precisamente nelas se pode divisar irrupções do social no cênico. Interessa neste texto o mesmo que interessa nas obras das quais emergem os questionamentos aqui desenvolvidos a partir de um marco epistemológico específico: é possível encontrar no peso e na bichice alguma positividade? Ou ainda: o que somente a negatividade de corpas gordas - pesadas e femininas/bichadas - permite perceber? A hipótese que se divisa no horizonte desse debate é que a saturada negatividade destas corpas emergentes pode desencadear uma ordem específica de cura: a compreensão de que não há doença, mas um projeto de adoecimento. Uma vez que aqui se escreve sobre a dança opta-se por abrir o debate com um duo coreografado nas lembranças coincidentes das obras.

\footnotetext{
${ }^{3}$ Neste texto utilizaremos o termo corpa para se referir àquelas que estão em engajamento de luta contra os sistemas normativos opressores e corpo quando nos referimos a ideais que estão em uma condição alienada e alienadora no que se refere a gordura. Opta-se, portanto, pela articulação de um "nós" calcado nas demandas dos transfemenismos afirmando-se a partir da utilização e criação de palavras no femino.
} 
Figura 1 - Banalidades - Colagem com imagens dos solos Peso Bruto (Elenize Dezgeniski, 2017) e Ensaio sobre a retórica (Karin Serafin, 2019) e texto descritivo a partir da memória de assistir uma à outra. Fonte: Acervo de Anderson do Carmo e de Jussara Belchior.

O começo dePeso Bruto é um tédio, um silêncio espesso, uma respiração profunda e bufada cortando o silêncio espesso. Uma orquestra de bufos e silêncios espessos. Um olhar devolvido, um olhar sustentado, uma ausência de pressa no olhar. Como se a pressa fosse algo que não existisse. Cem pessoas fisgadas por esse olhar. Tudo isso antes de a dança de fato começar. Assim que o "nada acontece" ultrapassa a linha do suportável. A franja presa atrás da orelha pende para o mesmo lado que a corpa se dependura. Uma cortina tapando os óculos, perturbando a teia invisível que se estendia entre as retinas. De repente uma corpa na diagonal. De repente um volume desequilibrando o espaço. Uma agonia constante, atenção escapando das ações da corpa para reação do banquinho de plástico no qual ela está sentada. Um alívio cada vez que este não quebrava. Um alívio quando este é deixado de lado. Ensaio sobre a retórica começa com uma chegada descompromissada com papéis na mão e uma garrafa d’água. Isso aqui é uma palestra? Pausa para tomar um ar. Tem algo a dizer, mas não sai nada. A boca não abre. Algumas tentativas frustradas e nada. Está impaciente? Pfft! Põe um ovo da boca. Era isso, tinha algo preso na garganta. Algo que não dava para engolir, nem botar para fora. Agora saiu. Agora vai dizer alguma coisa importante. O peito enche de ar, mas da boca só sai um som incompreensível. Nada demais. Parece que faltam consoantes, faltam vírgulas e sobram reticências. No meio de tudo isso, as perguntas. Como? Uma chuva de papéis. Um impasse na comunicação. Impasse? Nem tanto, dessa língua de sons prolongados e graves sai uma dança. Som da corpa toda. Dança falante. A unha, comprida e pontuda também fala. Aponta para os lugares, ocupa os espaços. Tudo está embolado: a urgência, a prepotência, a justificativa, a sedução e o deboche. É que está sempre tudo junto mesmo. Não tem nada de didatismo. Ou tem? Parece que escapou algo. Não, não foi por acaso. Disse alguma coisa. Tem alguma coisa escondida, ou brotando. Era francês? Inglês? Não importa, entre o óbvio e o que vai criando sentido a corpa dança. 


\section{Segundo gesto: "strip tese" do cuidado}

Figura 2 - "Strip tese" do cuidado - Colagem com imagens dos solos Peso Bruto (Nityama Macrini, 2017) e Ensaio sobre a retórica (Karin Serafin, 2019) e texto descritivo a partir da memória de assistir uma à outra. Fonte: acervo de Anderson do Carmo e de Jussara Belchior.

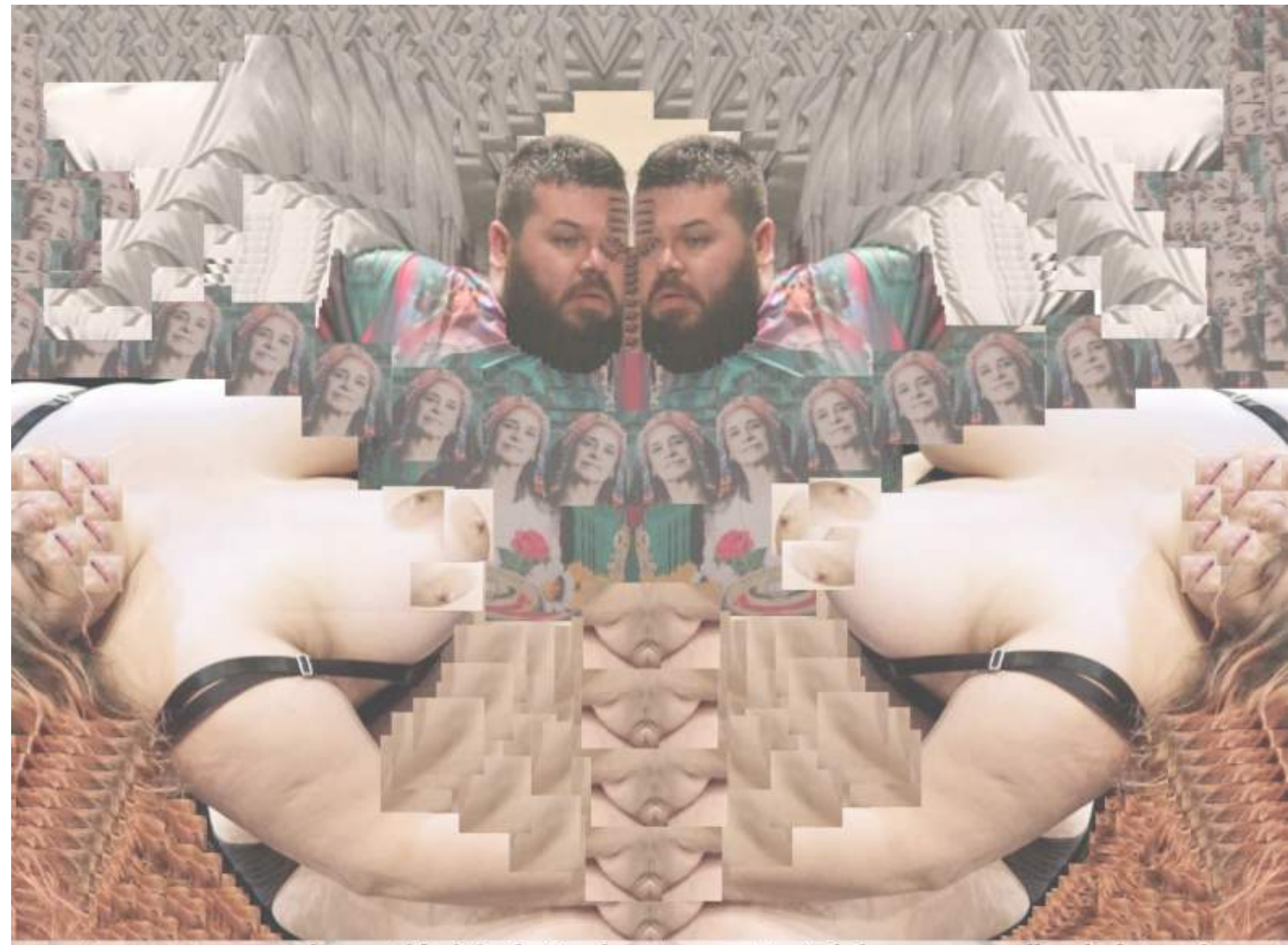

Uma surpresa quando o vestido é tirado. Renda e strass pretos. Pele branca se espalhando farta pelo chão. Pernas erguidas. Braços fazendo a vez de travesseiro. De novo um tédio, um silêncio espesso, uma respiração profunda e bufada cortando o silêncio espesso. Espreguiçar. Chão, parede e ar esculpindo a gordura e - também - pulsação de uma explosão representada no gráfico de uma

função em um plano cartesiano. A música ganha o espaço junto da corpa que é palimpsesto, mosaico, atlas, mapa, enciclopédia, dicionário bilíngue, hieróglifo, pixo cobrindo o outdoor. Peito escapando do sutiã, cabelo batendo, coturno sapateando. Gordura, unha, suor, cabelo, dente e saliva: campo de forças sem hierarquia estriando o espaço. Vênus de Willendorf, silêncio de mar vazio, parada de mão, árvore centenária, rochedo, céu estrelado em cidade de interior. 0 ambiente avermelhado, um foco de luz e uma música dançante. Da garrafa um creme branco que ela espalha em sua pele. Dos pés à cabeça. Momento monange. Autocuidado. Gorda cheirosa. Para a segunda garrafa um pedido ou um convite. Abre para mim? As vezes até um toque gentil. O líquido branco escorre pela boca. Gula e prazer.

Tem mais coisas para sair dessa corpa. Um incômodo, respira fundo, as mãos chacoalhando, os pés saltitantes e os olhos que desviam do que não aguentam mais ver. Sai saracoteando, a respiração acelerada, andando em círculos. Manobra a corpa para se livrar do que está por dentro, ou por baixo. Strip tease narrativo da bicha dançante. Do peito um sutiã. Da púbis um colar de pérolas. Da bermuda um rabo pendurado. Cher. Sereia. Maria Bethânia. Carnaval de divas. Um balão murcho saiu do cu. Arremessa tudo ao longe. Um alívio. A corpa se acalma e a fala acelera. Deita-se nesse espaço cheio de cacos e vestígios. Tudo vai ficando mais grave. Uma seriedade sustentada em uma pausa estapafúrdia. A corpa e sapo-ginasta falando como se pudesse fazer o chão vibrar. Tem algo muito importante para acontecer. Ou parece que tem. Ou parecia, não parece mais. Já foi. Era só isso mesmo. Anúcio de que mesmo? Agora ri da nossa cara. Risada aguda. Encantamento fatal. Uma língua que não se ouve por aí. Bem aguda, bem bicha. 
Terceiro gesto: nosso sonho é seu pesadelo, ou, "não deixar dormir quem não nos permite sonhar” (Mallmann, 2020, s.p.) ${ }^{4}$

Figura 3 - Nosso sonho é o seu pesadelo - Colagem com imagens dos solos Peso Bruto (Nityama Macrini, 2017) e Ensaio sobre a retórica (Karin Serafin, 2019) e texto descritivo a partir da memória de assistir uma à outra. Fonte: acervo de Anderson do Carmo e de Jussara Belchior.

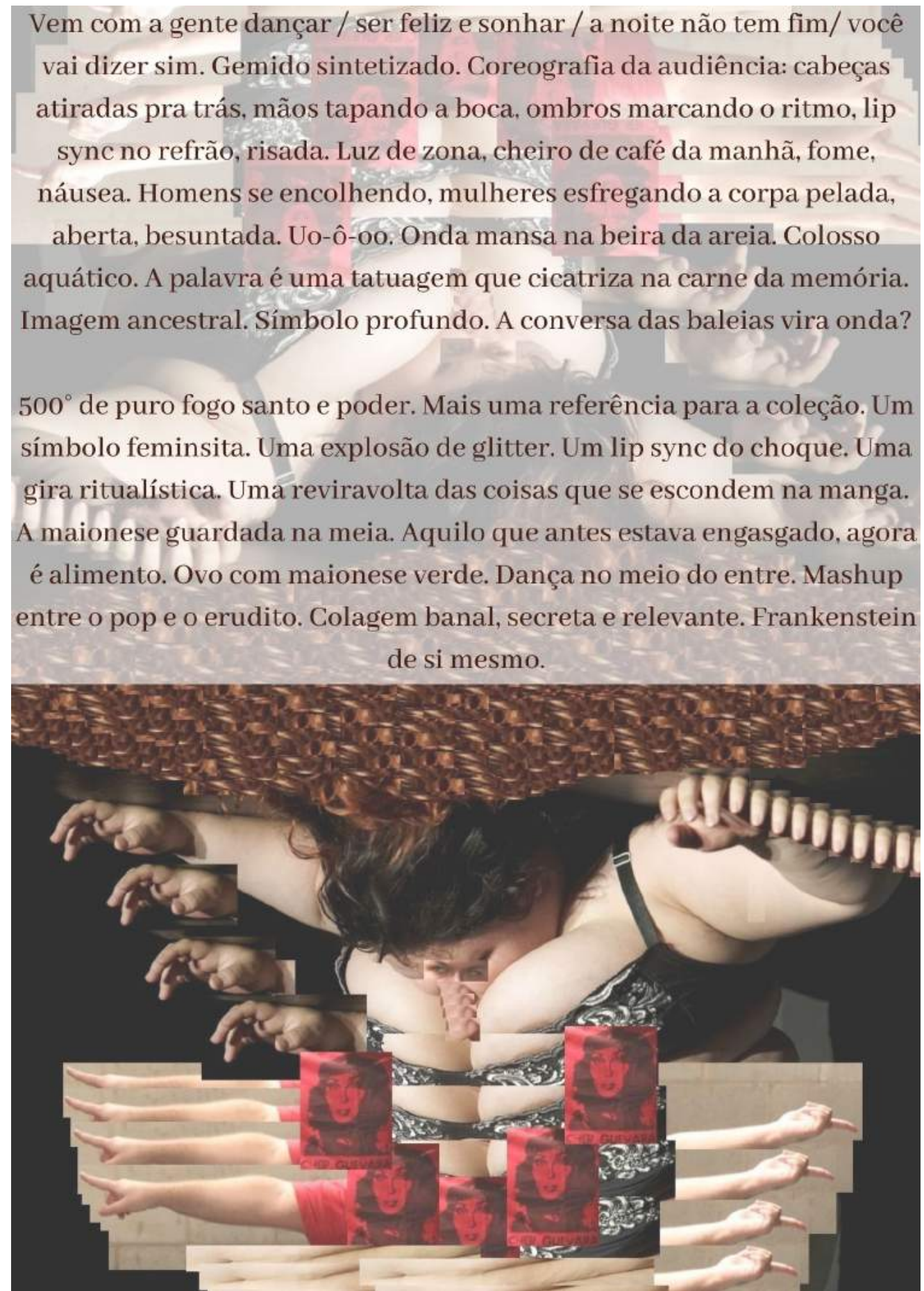

${ }^{4}$ Disponível em: https://www.instagram.com/p/CImHOozAVKv/. Acesso em: 14 jan. 2021. 
Repetindo o primeiro gesto: a banalidade de sentir-se no direito de dizer "você está acima do peso"

Ao entender a dança menos como uma forma que se fixa, e mais como uma travessia constante caberia retomar por onde começa este percurso que aqui se narra. Tendo primeiramente se encontrado ao integrarem o elenco do Grupo Cena 11 Companhia de Dança contexto no qual duas questões centrais para essa travessia já estão presentes, mas em outras condições de existência. Jussara Belchior Santos e Anderson Luiz do Carmo ${ }^{5}$ colaboram em projetos artísticos e acadêmicos ao longo dos últimos 9 anos, trabalhando com a linguagem da dança contemporânea, partilham o treino físico intenso e prolongado como marca de suas trajetórias artísticas e compõe obras com elaborados níveis de controle corporal e vigoroso gasto energético. Não contando com lesões significativas e tendo experiências em distintas técnicas somáticas e práticas corporais a materialidade das corpas da dupla de artistas autoras deste texto subverte o senso comum e se propõe a reclamar as imagens pejorativas de corpos gordos produzidas e agenciá-las por meio de ferramentas coreográficas em fluxos discursivos subversivos que interpelam a abjetização e a patologização compulsória dos corpos gordos.

No contexto de treino e performances do Grupo Cena 11 Companhia de Dança o peso e o erro são instâncias primordiais da lógica investigativa e compositiva que o coreógrafo Alejandro Ahmed desenvolve junto à companhia. Tensão e relaxamento muscular, propriocepção do alinhamento ósseo e a substituição de uma coreografia fixa no tempo e no espaço por uma lógica de desencadeamento e contágio são centrais para Percepção Física e Composição Generativa, o conjunto de parâmetros motores que a companhia sistematiza ao longo de seus quase 30 anos de existência. Tais parâmetros - bem como o peso e o erro - sintetizam-se no que ainda hoje permanece como marca registrada do

${ }^{5}$ As autoras deste texto são uma mulher cis gorda e uma bicha gorda que se referenciaram no feminino em posicionamento contra a problemática neutralidade masculina. Daqui por diante serão referidas ao longo do texto pelos nomes artísticos: respectivamente Jussara Belchior e Anderson do Carmo. 
grupo: a queda6.

Desde uma perspectiva tradicional a queda, dentro do campo da dança, é uma falha, um erro, uma interrupção daquilo que sucede. Em uma sucessão de passos pré-determinados a queda aparece como evidência de uma incapacidade de resistir à gravidade. A queda como arranjo motor no Grupo Cena 11 Companhia de Dança aparece em um contexto de experimentação de diferentes técnicas (jazz, balé, fly low, ioga) e atravessada por imagéticas opostas à da compreensão etérea da dança: o palhaço, os videogames, os quadrinhos são subtextos facilmente discerníveis a partir da estreia, no ano 2000, da coreografia Violência, que inscreve definitivamente o grupo no cenário contemporâneo nacional.

A queda como evidência de falha é tecnicamente construída, de modo que um nível de relaxamento em conjuntos musculares específicos permita que a gravidade leve o corpo até o chão em função de seu peso e - por meio da tensão em outros grupos musculares - mantendo um alinhamento que proteja as extremidades ósseas. A potência da queda é creditada ao artifício de criar uma perturbação perceptiva com o impacto do corpo contra o solo por meio de um refinado controle técnico que protege este corpo de machucar-se. Enquanto dor e machucaduras inevitavelmente mediam a recepção da plateia, por parte do performer sucede a rotineira realização de uma série de protocolos motores. Aqui a lógica dos games, quadrinhos e do palhaço se evidencia: a queda não desencadeia perturbações emocionais em quem dança, é apenas mais um passo que não interrompe um continuum coreográfico e alimenta uma impressão de virtualidade do corpo. As fórmulas, no entanto, são afetadas quando a variável de peso não corresponde ao que se considera, mesmo que de maneira inconsciente, o "normal" e o real atravessa o cênico.

A questão da qual se procura aproximar poderia ser sintetizada do seguinte modo: quando um corpo gordo habita um contexto artístico que se articula em

\footnotetext{
${ }^{6}$ A dupla que assina este texto já debateu específica e detalhadamente os arranjos motores da queda. Cf. Do Carmo, Anderson do Carmo e Jussara Belchior Santos. Ter corpo e ser corpo: percurso para uma dança da disponibilidade. [s.l.] In: Revista Carbono, 2013. Disponível em: http://revistacarbono.com/artigos/05ter-corpo-e-ser-corpo-cena11/. Acesso em: 30 nov. 2020.
} 
torno de ideias relativas ao erro e ao peso se torna inevitável que uma dimensão do real perturbe a prática artística e frustre o sistema estético já estabilizado em função de ditas ideias. Nesta lógica, em qualquer rotina de treino e performance de engajamento corporal intenso, um corpo gordo não lida com o seu peso "real" - o que sucede com os corpos magros - mas sim com (1) uma representação prévia de como o peso desencadeia movimento e (2) com a tensão social e psíquica compulsoriamente atribuída ao comportamento de seu corpo pesado e compreendido simultaneamente como fruto de erros e propenso a errar.

Esta articulação pretende menos apontar uma inconsistência na prática do Grupo Cena 11 Companhia de Dança e mais uma tendência de contextos ditos contemporâneos comporem dentro de um regime de abstração que não sustenta a materialização de instâncias como o real, o político, o social. O temor em reduzir-se ao panfleto localiza a prática no tempo e no espaço e força a apresentar a seguinte questão: quem tem o privilégio de não precisar de panfletos?

\section{Repetindo e transformando o segundo gesto: "strip tese" da} leveza

Hidratar a corpa, como faz a bailarina gorda em Peso Bruto, é uma ação que pode ser rotineira para muitas pessoas. Além de cuidar da pele ressecada, envolve um cheiro agradável e um momento de intimidade de tocar a própria pele. Para as pessoas gordas, hidratar-se pode ser também uma tentativa de proteção contra comportamentos gordofóbicos. Por serem consideradas nojentas e desleixadas algumas pessoas gordas se esforçam para quebrar esse imaginário mantendo-se cheirosas e bem vestidas. Em cena, esse momento é apresentado como um exagero. Um cheiro inebriante, que invade a plateia, e o excesso de creme que deixa a corpa toda melada, perturbam a percepção que se tem da corpa que dança. Na segunda garrafa - cujo conteúdo não se pode precisar qual é - a corpa gorda quer mais, quer se alimentar desse zelo. Engole e baba. O líquido escorre pela boca. Um misto de prazer em se cuidar e de fazê-lo em demasia. O zelo, a gula e a confusão dominam as ações que deformam o 
rosto e espalham-se pelo chão. Há um questionamento sobre o controle que o cuidado estético tenta efetivar sobre essa subjetividade nesse exagero em cuidar-se.

Tirar o sutiã e deixar as mamas balançarem, por sua vez, é uma ação que remete a liberdade, a não condescender com as medidas de controle das corpas. O cuidado está em escutar a própria corpa e atender as necessidades de conforto. Cada vez mais pessoas gordas ou magras, de peitos grandes ou pequenos, têm aderido a esse movimento, que é decorrente do imaginário relativo às práticas feministas de queimar os sutiãs. A reviravolta presente em Ensaio sobre a retórica é que quem tira o sutiã não é uma mulher cis ou trans, mas uma bicha gorda que dentro da ficção faz uso da peça de roupa em questão para - inicialmente - ocultar o volume de seu peito. É até comum que homens gordos tenham gordura peitoral que se assemelham às mamas, mas não é esperado que eles usem sutiãs. Ao contorcer-se para tirar a peça de roupa sem despir a camiseta, a artista quebra com a norma e avança na discussão sobre controle das aparências das corpas nos âmbitos das questões de gênero. A bicha pode usar sutiã? Mesmo sem estar montada? Quem precisa de sutiã? Um homem com peitos grandes precisaria controlá-los para sua pertença a masculinidade não entrar em risco? Quem precisa modelar o corpo para enquadrá-los em certos padrões?

As friç̧ões no entendimento de autocuidado trabalhadas nessas cenas dialogam com a crítica do filósofo francês Gilles Lipovetsky a respeito da imposta necessidade da atual sociedade capitalista em viver de forma leve, apresentada em seu livro Da leveza: rumo a uma civilização sem peso (2016). Segundo ele, nossa sociedade hipermoderna possui um estilo de vida que busca pela "fuga do estresse, alívio das tensões e restauração da calma, do equilíbrio interior, da harmonia do corpo e do espírito, as técnicas de bem-estar se impõem como o novo caminho para a leveza do ser" (Lipovetsky, 2016, p.82). Nesse contexto sucede a popularização de práticas como ioga, meditação e mesmo o turismo religioso arquitetado em função da ayahuasca: práticas cujas origens culturais se borram em favor da apropriação de aspectos que 
corroboram com o abandono de pesos psicossomáticos. É um imperativo de leveza se espalhando por todos os âmbitos da vida: leveza de se sentir confortável sem sutiã, de se sentir cheirosa e com a pele sedosa como quem toma tempo para cuidar de si ou por sentir-se em equilíbrio pelas práticas de atividades físicas e terapêuticas.

A leveza a qual o filósofo demonstra fazer parte da nossa era advém de uma dinâmica de sociedades modernas em "tornar a vida mais leve", ele explica:

Com o capitalismo de consumo, o triunfo do leve se lê tanto na vida material como na cultura, nas ideias e nos valores. Essa é de fato uma economia que se constrói moldando uma cultura de essência "leve", por estar centrada nos referenciais hedonistas e lúdicos (Lipovetsky, 2016, p. 41, destaque do autor).

São comportamentos em busca da leveza que se espalham nas dinâmicas do cotidiano. Lipovetsky entende que a demanda da leveza significa: velocidade nas relações, favoritismo por objetos de consumo cada vez mais leves e menores e na aparência das pessoas que devem ser leves e magras. Os comportamentos na sociedade da leveza são tomados pela urgência em estar no tempo presente, deixando de lado o peso das tradições na conexão com o passado ou a gravidade do futuro. Nesse sentido, vivemos um tempo em que "a relação despreocupada e leve com o presente vivido deve dar lugar às atitudes de prevenção, de vigilância e de correção dos fatores de risco" (Lipovetsky, 2016, p.80).

Os questionamentos trabalhados nas cenas descritas anteriormente especificamente na confusão e exagero do autocuidado e na disposição em estar sempre confortável - parecem balizar a imposição de leveza que acomete a nossa sociedade. O filósofo explica como esse desejo de leveza é contraditório ao passo que desperta um consumo frívolo assim como um ímpeto de viver de forma leve, na busca por um consumo mais responsável com o ambiente e seu entorno.

Nada escaparia ao capitalismo, nem mesmo as práticas mais avessas aos 
modos de vida alienados. Cooptadas pelo consumismo da leveza, "o avanço de novas espiritualidades, a busca de novas maneiras de consumir e viver que rejeitam as pressões materialistas do 'sempre mais'” (Lipovetsky, 2016, p. 63, destaque do autor). A sociedade da leveza exige das pessoas um comportamento leve, que inspire leveza e não instaure gatilhos de dores. Tudo isso para que o fardo da vida seja amenizado e um fluxo contínuo e ágil de informações e situações novas não fique em risco.

Livrar-se do sutiã pode ser uma ação de conformidade com a leveza de estar bem consigo mesma. Mas, ao ser realizada por uma bicha gorda a ação assume um caráter dialético, que dá outro peso a essa ação. Assim como o creme em demasia, a saturação de um cuidar-se transforma a leveza do cuidarse em leveza desenraizadora, apartadora de qualquer contato com a diferença em uma espécie de flutuação ideológica negacionista da gravidade: funcionando apenas em circuitos fechados.

Para se posicionar em função das distintas faces assumidas pela leveza é preciso engajar-se na paragem ${ }^{7}$ e permitir que o peso aja. Aqui o peso é entendido como força de equilíbrio, de fricção e de choque. Pesar sobre a demanda da leveza pode ser uma tática de posicionamento crítico. Esse peso funciona como um reconhecimento da própria corpa em suas proporções, suas medidas, do espaço que ocupa, da forma como se relaciona com todas as coisas e pessoas ao seu redor. Um peso que permite a corpa sentir o vento das regulações sem se deixar flutuar. Peso que - talvez o aspecto mais importante para a presente reflexão - não se modifica facilmente e cuja mudança é impossivel ignorar.

Nessa medida, é pertinente observar ambos os solos desde as escolhas de seus títulos: se Peso Bruto vai fazer referência a terminologia comercial que além do peso de um produto contabiliza também suas camadas de embalagem e

\footnotetext{
A noção de paragem aqui é evocada a partir do que o pesquisador da performance e da dança André Lepecki articula em Exaustig dance (2010), na medida em que esta se diferencia da pausa. Enquanto a pausa sugere a interrupção de um continuum de movimento a paragem - terminologia oriunda do português de Portugal - se refere a ausência de movimento externo evidente em favor de uma intensificação dos movimentos internos e imperceptíveis. A paragem em sua ausência de deslocamento chama atenção para a reverberação do passado no presente e - em diálogo com o filósofo Peter Sloterdijck - se recusa a obedecer o imperativo de progresso avançando para o futuro.
} 
proteção, Ensaio sobre a retórica faz uso de um duplo sentido para referir-se ao mesmo tempo a abordagem ensaística sobre um determinado tema e a prática de ensaiar. Tanto a escrita quanto a prática se referem a retórica, de modo que o solo se ocupa da retórica ao mesmo tempo que ensaia para que esta retórica seja bem-sucedida. Ambas as intenções fracassam.

Aí o debate assume outra densidade: erro e falha - instâncias pertinentes no contexto do Grupo Cena 11 Companhia de Dança e outros ambientes de dança contemporânea - sugerem condições menos definitivas que a compreensão do fracasso. O fracasso é aqui convocado pois operaria fora da esfera do remediável e palatável, seria definitivo, indisfarçável e chamativo. E a tarefa radical de engajar-se no fracasso é poderosa, pois para ela não há solução ou tentativa de restauração: ela demanda a inauguração de outra instância de existência. Essa instância é especialmente importante ao pensar práticas de cura nas artes na medida em que ela permite que se construam contextos onde as corpas gordas percebam que não são doentes, mas adoecidas e que - nesse encalço - não há o que curar pois não há doença e sim uma existência que não consegue ser percebida pelas narrativas dominantes para além da patologia.

Interessa observar como um engajamento e uma virtuose no fracasso conectam esses dois solos uma vez que ambos alegorizam atravessamentos sociais e políticos da corpa gorda e suas intersecções com os debates de gênero, sexualidade e diversidade funcional. O engajamento e a virtuose no fracasso, importante ressaltar, se articulam como meios de sabotar a lógica patologizadora instalando um outro modo operativo que confunde a economia pautada no sucesso. Esta é uma escolha que se afasta de abordagens aconchegantes que operam com o vocabulário da superação, de positividade e das várias hashtags - \#bodypositive e \#corpolivre - que se acumulam ao redor da noção já capitalizada de corpo livre. Há uma acolhida do deboche, da subversão e da saturação de narrativas abjetizantes.

Peso Bruto inicia com a interação entre uma corpa gorda e um banco de plástico - cenário clássico de tensão e expectativa de desastre-para-rir - satura a exposição das carnes fartas, cansa a corpa em demonstrações de controle e 
força, satura imaginários de sensualidade comercial por meio de lingeries e a aplicação de creme, ostenta o clichê da gula embalado pelas vozes do grupo pop Fat Family encerrando com o aparecimento da voz da dançarina mixada ao canto de baleias até que sua corpa abra espaço no miúdo espaço do público para se retirar da cena.

Ensaio sobre a retórica é uma palestra que não dá certo: em vez de voz o que sai pela boca é um ovo, os óculos são retirados e uma corpa que vê pouquíssimo insiste em tentar falar com interlocutores que praticamente não enxerga, não conclui nenhuma palavra pois soluços, arrotos, lágrimas e risos the atacam, se revela que a corpa masculina que dança escondia peitos grandes com um sutiã, se retira um colar de pérolas que aumentava o volume da cueca, o cu se abre para que um balão seja dali retirado e soprado até explodir seu interior de purpurina.

Ambos os solos, compostos dentro das linguagens da dança contemporânea, servem-se de situações que orbitam a dimensão do fracasso. Mais que isso: ambas as corpas que dançam - uma mulher e uma bicha gordas, grandes, pesadas - se utilizam da expectativa de fracasso que lhes é compulsoriamente atribuída. Sucede - de modos distintos em cada obra - o desenvolvimento de uma estratégia que não procura criar um universo à parte da injúria, mas que a rouba, toma-a pra si e reinventa esta injúria por meio da subversão, criando um alternativo e efêmero regime valores e verdades.

Esta estratégia coreográfica ressoa fortemente a leitura que o teórico queer estadunidense Jack Halberstam (2020) faz das ferramentas opositoras que James C. Scott (1987) chama de "armas dos fracos" e do qual Saidiya Hartman (1997) fez vasto uso abordando práticas de pessoas negras escravizadas. Para Halberstam:

O conceito de "armas dos fracos" pode ser usado para recategorizar o que parece inação, passividade e falta de resistência em termos de práticas de obstruir os negócios do dominante. Também podemos reconhecer o fracasso como maneira de se recusar a aquiescer a lógicas dominantes de poder e de disciplina e como forma de crítica. Como prática, o fracasso reconhece que alternativas já estão embutidas no dominante e que o poder nunca é total ou consistente; de fato, o 
fracasso pode explorar a imprevisibilidade de ideologias e suas qualidades indeterminadas (Halberstam, 2020. p.133, grifo nosso).

Importante distinguir aqui um engajamento em um processo de libertação de um engajamento numa resistência. Conforme Carlos Henrique Lucas Lima (2017), teórico brasileiro que pensa a hermenêutica da teoria queer em contextos racializados da América Latina, articula em função do que David Halperin (2007) chama de políticas opositoras: “[...] o propósito seria não a 'liberação’, mas sim, a própria 'resistência' como fim em si mesma. Talvez porque a liberdade não passaria [...] de uma ilusão do poder (Lima, 2017, p. 181).

Tanto a leitura das políticas opositoras quanto das armas dos fracos localizam o debate em uma negatividade que opera resistindo, opondo-se, obstruindo, recusando. Entende-se tais ações como negatividade em função de sua operacionalidade crítica suceder de dentro dos discursos dominantes criando tensões, estrias, rachaduras e abrindo espaços a serem ocupados. Com fortes ressonâncias dos postulados de Judith Butler (2015) e Michel Foucault (1997), ambos os operadores conceituais não concebem um fora do discurso, um fora das relações de poder ou um antes destes, de modo que a ação estética é operada na porção mesma da linguagem, discurso e poder que abjetizam a diferença.

No que concerne especificamente às cenas é, mais uma vez, na virtuose do fracasso que também se recusam a compor dentro de vocabulários estáveis da dança contemporânea que esse conjunto de reflexões pode servir como interlocução: Peso Bruto e Ensaio sobre a retórica (mesmo quando relacionados à Percepção Física e Composição Generativa desenvolvida por Alejandro Ahmed junto ao Grupo Cena 11 Companhia de Dança, técnica partilhada por Jussara Belchior e Anderson do Carmo e que se serve de noções de erro) o que sucede é um investimento das possibilidades técnicas que se dispõe em tarefas contextuais específicas e externas as preocupações a priori coreográficas.

Dito de outro modo: o fracasso em conseguir articular as palavras de um discurso, bem como o fracasso em poder sentar-se tranquilamente em um 
banco frágil não são ações da ordem do grandioso ou do espetacular mas, ao contrário, são profundamente banais e esse é o trunfo de suas dramaturgias. O investimento em ações cotidianas, corriqueiras, banais, bobas, irrelevantes evidencia uma espécie de ruptura com qualquer instância heroica, épica, homogeneizante e hegemônica. Essa ruptura, ao mesmo tempo que denuncia as instâncias do social que impedem os corpos marcados pela diferença de integrarem-se no contexto das hegemonias - a corpa gorda que não cabe nas arquiteturas e mobiliários compartilhados, a bicha cujo discurso tem qualquer assimilação cognitiva recusada - devolve essas violências criando contranarrativas que perturbem e (mesmo que momentânea e transitoriamente) aniquilem a norma.

Se as corporeidades gordas que dançam em Peso Bruto e Ensaio sobre a retórica interrompem um pacto de patologização - uma vez que uma economia alternativa para seu menor ou maior engajamento nas ações - não deixa de existir em tal interrupção uma dose de deboche capaz de articular o oxímoro "virtuose do fracasso": As corporeidades de Jussara Belchior e de Anderson do Carmo são treinadas em técnicas contemporâneas e experientes em educação somática; tem, portanto, condições de produzir mobilidade coreográfica, de suportar esforços prolongados administrando energia e realizar peripécias corporais que a maior parte dos corpos ditos normais - o que neste contexto quer dizer "magros" - sem treino não tem condições de realizar sem desencadear lesões. Tais habilidades, em função de uma preconceituosa expectativa socialmente construída, não são concebíveis em corpos grandes, gordos, pesados, flácidos e que em todos os aspectos destoam das certezas capacitistas e patologizantes.

Precisamente nessa articulação - do corpo gordo não evidenciar aquilo de que é capaz - reside a possibilidade de devolução da violência de caráter gordofóbico. No vazio que se rasga na percepção de quem assiste as obras e se espanta como aquilo que estas corpas podem fazer apesar de sua gordura, onde a performance não se dá desde a ostentação do que se pode fazer antes mesmo de ser feito. No caso de Peso Bruto e Ensaio sobre a retórica a crença 
preconceituosa e gordofóbica em relação a limitações motoras de corpos gordos é dado fundamental das dramaturgias que se realizam quando a tal certeza é perturbada e algo considerado impossível do ponto de vista médico, estético e cultural - o corpo gordo ser habilidoso, disciplinado e eficaz - sucede. Nesse estriamento dos pressupostos se abre um espaço para que (1) a ferida social da injúria seja percebida por aqueles que nela costumam jogar sal e para que (2) a noção de peso seja incluída em um horizonte que inclua significados mais vastos que a ofensa.

\section{Repetindo o terceiro gesto: pesar - entre o sonho e o pesadelo}

A ação de pesar pode ativar nos corpos um comprometimento simultaneamente material e simbólico que não está apenas pautado no presente que ignora os pesos do passado e futuro, como se estes nos impedissem de viver o agora da melhor maneira, ou seja, da maneira leve. Pesar como estratégia de posicionamento e luta política - pesar o clima, usar palavras pesadas, ter os discurso adjetivado como pesado - é reconhecer os pesos que nos moldam sem compreendê-los como fardo intransponível, mas como campos de forças que demarcam nossa posição no tecido social. Conectar-se com essas forças reivindica uma presença impregnada de passado - aqui compreendido como processo de constituição corporal - e das possíveis invenções de modos de existência para o futuro.

Essa articulação permite convocar o "anjo da história”, apresentado pelo filósofo e crítico alemão Walter Benjamin (1987, p. 226) na tese 9 de seu texto Sobre o conceito de história (1987). O anjo encara a tempestade do progresso, soprada do paraíso, com suas asas e olhos bem abertos encarando as ruínas acumuladas pela força do progresso e da barbárie. Ao ser lançado para o futuro o anjo contempla os destroços, os mortos e os esquecidos e deseja trazê-los consigo. Segundo Benjamin, essa é a tarefa do materialista histórico, trazer consigo o que caiu no esquecimento para contar a história dos vencidos. 
Nessa articulação, o materialista histórico não veria, quando mirasse uma pessoa gorda, um corpo arruinado, indisciplinado e fora de controle em seu consumo de alimento. O que poderia ser observado são processos de mudança dos estatutos de beleza e das noções de saúde. Sob o olhar do materialista histórico a ruína com a qual o anjo se defronta não é corpo com gordura acumulada, mas a falência das narrativas ciclicamente articuladas com o objetivo de controlar a operacionalidade, produtividade e aparência dos corpos por meio do consumo de alimentos, exercícios, roupas e cosméticos que prometem uma espécie de mais-valia de vitalidade. O anjo se depara com as histórias dos corpos excluídos por um processo progressista, capitalista, normativo e homogeneizante. Ao observá-los reconhece nelas a possibilidade de pesar contra a tempestade do progresso.

O peso do anjo poderia ser uma força contrária ao vento do progresso ou contrária a demanda da leveza e de sucesso: apesar da velocidade e da força do vento divino, o peso do anjo pode impedir que ele seja atropelado pelo progresso. A pintura Angelus Novus (1920) de Paul Klee, que inspira a escrita de Benjamin, apresenta um anjo de asas e pernas pequenas e uma grande cabeça que representa quase metade de sua altura. A grande e pesada cabeça poderia pender para alguma direção demorando-se em observar a destruição. Deslocando seu centro de gravidade, interferindo assim, no modo como o vento carrega seu corpo. O anjo que pesa poderia entrar em um jogo de forças com o vento, provocando desequilíbrios a si mesmo, podendo assim se aproximar daquilo que contempla e alcançar as vidas que têm ficado para trás.

O anjo não deve se importar em "pesar o clima" ou de se aproximar do que "deu errado", pois o peso que se instaura é desencadeador de outra ordem de movimento, não de estagnação. Ao contrário de sermos carregados como plumas para o futuro, ao reagir com o peso podemos perceber a força do vento, perceber nossas fraquezas e criar estratégias de posicionamento e reação coletivamente. A ação de pesar é uma ação de resistência, para resistir a tempestade é preciso acionar a força do peso da corpa, das palavras, da memória e do coletivo. 
Peso é palavra, ideia, coisa raramente associada com alguma ordem de positividade: se tira um peso dos ombros, se sente um peso no peito, o clima pesa, algo fica por demais pesado para se sustentar. Em compensação a leveza é característica desejada, é elogio, sinônimo de acolhimento. Há outras cicatrizes sociais que se evidenciam em oposições aparentemente inofensivas: esclarecer um argumento necessariamente articula a compreensão de que aquilo que é escuro atrapalha um debate. Um debate fértil desenha um cenário onde apenas relações (re)produtivas têm valia, do mesmo modo que uma transição orgânica (natural) entre cenas implica um demérito daquilo que é sintético e não colabora com a ficção de natureza. Uma desculpa capenga sugere que aqueles que tem no corpo diversidades funcionais não funcionam bem. A lista de exemplos poderia se prolongar, no entanto cabe pensar, na esteira da interpretação que Butler (2015) faz dos atos de fala de Austin (1990) - que a capacidade performativa da linguagem criar realidades pode operar como unguento curativo a ferida da injúria.

O movimento negro é exemplar nesse aspecto na medida em que passa a propor articulações como "escurecer a questão" e chamar, consequentemente, atenção para o fato de que se a clareza permite uma visão límpida no escuro, onde a luz não chega podem existir coisas que demandam outros aparatos perceptivos que não os do já deveras colonializado olhar. Partindo deste pressuposto se poderia investir em uma deriva da palavra: uma deriva que atravesse de visceralidade o semântico e sature, amplifique, avolume e adense "peso", "gordura”, "flacidez", "estria” para além da patologia e do juízo estético, para além da funcionalidade e do julgamento moral. Qual seria a positividade do peso? Ou o que apenas a negatividade do peso poderia revelar?

A mobilidade daquilo que pesa é uma negociação colossal, o peso firma posição, estabiliza permanência e abala profundamente qualquer estrutura quando por ela se desloca. A ação do peso não deixa dúvidas de seus impactos e não pode ser disfarçada. O peso não pode ser ignorado.

${ }^{8}$ Essa reflexão se encontra formalizada em Problemas de gênero: feminismo e subversão da identidade. Rio de Janeiro: Civilização Brasileira, 2015. 


\section{Repetição dos gestos: \\ processos de estriamento contra o medo da engorda}

As banalidades, erotismos e sonhos que gerenciam os trabalhos das artistas autoras deste artigo se entrelaçam como práticas que reconfiguram os discursos manipuladores de vidas. Nesse sentido, um passo importante é o reconhecimento das violências que sofrem as corpas dissidentes e as estratégias que podemos criar para desarticular o sistema opressor. A pesquisadora e performer brasileira Jota Mombaça (2016) explica que é preciso encarar as violências que nós somos capazes de produzir. Segundo ela, “é preciso articular os processos de redistribuição da violência com outras formas de cuidado, partindo do princípio de que é tão fundamental abraçar a própria violência quanto tornar-se responsável por ela” (Mombaça, 2016, p. 15). É preciso reconhecer os processos de violência que atravessam nossas corpas para então reconhecer a violência como força revolucionária de ação contra-hegemônica.

O interessante é que a proposta de redistribuição da violência de Mombaça vislumbra possibilidades de autodefesa, que podem ser entendidas como formas de cuidado. Para tanto, é preciso se voltar a própria corpa:

Há muitas formas de treinar e de pensar autodefesa. Num primeiro plano, há o treinamento físico e seus impactos sobre o corpo, mas nem todos os corpos treinam da mesma maneira. É preciso, nesse processo de reapropriação subalterna das técnicas de violência, saber reconhecer os modos como cada corpo elabora sua própria capacidade de autodefesa. Parte desse trabalho consiste, portanto, numa mudança radical de percepção (Mombaça, 2016, p. 13).

Dessa forma, a autodefesa se configura como um caminho de cuidado dialético, que abraça as medidas de proteção e de reação. Em Peso Bruto e Ensaio sobre a retórica as violências que atravessam as histórias das artistas se transformam na medida em que propõem uma trajetória de inversão: da fala incompreensível e do equilíbrio arriscado para as tensões do desimportante; do despir-se para a saturação do cuidado e a desmedida das aparências, e da 
exposição da gordura para o choque das narrativas estriadas pelo peso e pelo fracasso.

A percepção entre o que pode e o que se espera dos corpos gordos são chacoalhadas quando se inverte a lógica imposta. A violência contra as pessoas gordas, que por vezes parece ser tão sutil, é escancarada nas expectativas que se quebram e se reajustam nessas danças pesadas e fracassadas, virtuosas e banais, sedutoras e perturbadoras.

Das violências mais recentes contra as pessoas gordas durante a pandemia se percebe como um certo pesadelo em relação ao peso e o suposto fracasso em se adequar a norma passa a despontar em forma de memes. Em virtude do isolamento social adotado em meados de março de 2020, como medida preventiva a proliferação da COVID-19, um novo imaginário relativo aos corpos gordos floresceu. Um dos aspectos mais verificáveis nos memes, lives e textos publicados nas redes sociais e plataformas de compartilhamento de conteúdo dizia respeito a uma comparação entre o antes e o depois da materialidade de corpos que engordam quando impedidos de circular no espaço público e condenados a permanecer em casa. Esse imaginário implica que necessariamente o impacto do isolamento sobre os corpos seria a engorda na medida em que - segundo esse imaginário - se limitando ao perímetro de nossas casas tudo que nos restaria fazer seria comer e entregar-se a letargia.

Essa lógica revela uma naturalização da gordofobia, um temor em se assemelhar a algo que não consegue ser percebido para além da doença, da feiura e da preguiça. Essas piadas revelam também um bem-sucedido processo de disciplina e controle na medida em que ante a mais sutil perturbação das rotinas se teme perder o controle sobre si e engordar. Revela-se aí uma assustadora ignorância em relação aos processos metabólicos dos próprios corpos e averígua-se o fato dos transtornos de imagem corporal serem mais frequentes do que o que se poderia supor.

As imagens adotadas nesses comparativos cômicos idealizaram um "antes" por meio de formas atléticas, de profissionais do esporte, modelos, bonecas 
Barbie e desenhos animados de artes marciais, não raro registrados em ensaios profissionais. Corporeidades que - para manterem-se nestas configurações recebem total dedicação, amplo acompanhamento médico, de treino e interferências cirúrgicas de modo a se encaixarem o máximo possível dentro de um ideal padronizado de beleza. As imagens do "depois" são de pessoas gordas em fotos amadoras, sem qualquer domínio técnico na produção imagética e necessariamente capturadas em momentos de desequilíbrio, queda, relaxamento despreocupado com a imagem que se estava projetando. As imagens de pessoas gordas poderiam ser também montagens propositadamente toscas que manipulam figuras de personagens populares de modo que não coubessem em suas roupas ou ficassem impedidas de realizar atividades pelas quais são conhecidas.

Em contrapartida dessa produção gordofóbica as artistas autoras deste artigo se juntam para criar através de ferramentas coreográficas, digitais e textuais o trabalho T.R.A. (técnicas para retardar a antecipação [ou] trabalho

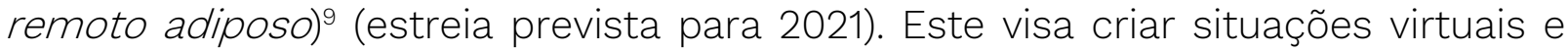
físicas de pesquisa e formação que comportem aspectos de investigação, criação, análise e discursividade da imagética da corpa gorda em uma perspectiva crítica e contra-hegemônica. Se apropriando tanto de narrativas capacitistas abjetizantes (que reduzem o corpo gordo a condição de doente e preguiçoso) quanto de discursos libertários neoliberais (que reduzem o corpo gordo a mais um nicho consumidor).

Nesse contexto, percebe-se a possibilidade de investigação estética por meio de uma produção coreográfica que perturbe tais percepções fixadas sobre magreza/gordura, capacidade/invalidez, desejo/repulsa, saúde/doença e provoque uma reflexão em relação às narrativas de vigor, leveza e sucesso creditadas a corporeidade controlada e as narrativas da preguiça, do peso e do fracasso que a corporeidade que resiste a se padronizar - e teima em ocupar mais espaço do que deveria - recebe. Esse é o disparador criativo para a dupla de artistas encontrarem-se precisamente por suas experiências corporais

\footnotetext{
${ }^{9}$ Projeto contemplado pelo Prêmio Elisabete Anderle de Estímulo à Cultura 2020.
} 
contradizerem a narrativa capacitista a priori creditada ao corpo gordo.

O território estético proposto é nomeado por meio de negociações semânticas e vocálicas em torno da sigla T.R.A. Se tomada como onomatopeia (TRA) a sonoridade sugere movimentos bruscos, quedas, golpes, rasgadura, interrupção, percussão; é uma das onomatopeias que drag queens utilizam para se referir ao propósito de roubar o foco que a abertura de seus leques causa, em uma espécie de rasgadura brusca e ostensiva de vitalidade. Já técnicas para retardar a antecipação e trabalho remoto adiposo jogam com significados das palavras para nomear sensações e projetos contraditórios que invadem nosso afeto neste momento da pandemia: desenvolver técnicas que retardam a antecipação é uma escolha por não se alienar deste momento de isolamento, solidão e incerteza - um momento pesado - se rendendo ao sonho sobre um mais leve - futuro. Ao contrário: a hipótese que se articula é de que ao retardar qualquer sentimento de antecipação e mergulhando nas contraditórias sensações que nos acometem dentro de casa, bem como com as informações vindas de fora, se poderá descobrir e inventar outros modos de estar em espaços públicos e compartilhados. O trabalho remoto, expressão popularizada do dia para noite, se coaduna a expressão "adiposo" não apenas pela materialidade gorda das corpas que trabalharão remotamente porém em consonância, este se refere também a densidade, textura e tônus que se almeja para a dança aqui pesquisada: uma dança grande, chamativa, que ocupe espaço e pareça transbordar para onde não devia.

A estratégia para o novo processo dessa parceria tem como ponto de partida um entendimento de que a própria gordura é capaz de balizar o imperativo de cura que acomete as pessoas gordas. Reconhecer e celebrar a própria gordura propõem novamente uma trajetória de intrincamento entre as banalidades, erotismos e sonhos relativos às corpas gordas. Nesse sentido, a proposta de T.R.A. dialoga com a pesquisa somática de Jules Pashall (2018), que em seu processo de reapropriação de sua gordura explica que "uma vez que a patologização e a humilhação de minha gordura foi o veneno que me afastaram de meu corpo, remover as toxinas e tornar a gordura em remédio foi como pude 
me recuperar" (2018, p. 71) $)^{10}$ Neste texto, Pashall articula como nossa corpa, nossa história e sabedoria, podem se tornar remédio para lidar com as dores que a sociedade capitalista nos inflige.

Pashall nos ensina a retornar para a própria corpa, para perceber onde se acumulam as dores - como um nó preso na garganta - para então espalhá-las pelo resto da corpa, isto é, lidar com as situações de corpa inteira. Ao falar sobre a particularidade de sua corpa gorda, Pashall agradece sua banha por ter mais espaço para espalhar e dissipar a dor. Ensina-nos também que esse processo pode acontecer tanto por uma dor que nos foi causada como por uma dor que nós tenhamos causado. Nesse sentido, este também parece ser um processo de cura e autocuidado que trilha um caminho de reconhecimento das nossas próprias violências, para aprender a desviar das regras excludentes e da repetição de comportamentos abusivos.

Para nos remediar em um mundo doente que está o tempo todo intoxicando corpas dissidentes é importante encontrar formas de se relacionar com o próprio corpo que não acentuam as doses de veneno, as dores e as violências que nos oprimem. Criar gestos de peso nos ajuda a perceber o quanto as mudanças das estruturas precisam ser feitas coletivamente, para que as estrias possam sedimentar um espaço rugoso, flácido, fraco e por isso precioso. Se em Peso Bruto e Ensaio sobre a retórica as narrativas de gordura e bichice das artistas são tensionadas no palco, em T.R.A. o processo artístico se desdobra para o universo online de postagens regulares e uma maior interação com o público - e possíveis haters dentre eles. Esse processo que está por vir se engaja por uma luta interseccional, que se articula nas banalidades, sensualidades e sonhos de ser gorda.

No que concerne ao exercício de imaginação do que poderá vir a ser a formalidade performática articulada nas diversas fases do projeto T.R.A. dois aspectos devem ser observados com atenção.

O primeiro se refere aos usos que a compreensão de "gatilho" assumiu na 
contemporaneidade. Derivada dos usos da expressão inglesa trigger, a função do aviso de gatilho aparece como alerta prévio a exibição de filmes e séries - que em seguida se espalha para as artes presenciais - que contenham material sensível relativo a representações de abusos sexuais, suicídios e transtornos alimentares. Progressivamente tal alerta acolhe também avisos a diversas violências, em certa medida naturalizadas na produção artística: violência e morte de pessoas negras, violência doméstica, humilhações gordofóbicas e capacitistas.

O alerta prévio é um dado da ordem do cuidado endereçado a grupos já habituados ao trauma: não corroborar e fortalecer este trauma, entende-se, é postura engajada na produção contra-hegemônica e comprometimento com a resistência às opressões. Sucede, no entanto, uma complexa modificação na finalidade da expressão "gatilho": de alerta que dava escolha a audiência de ver ou não obra - "essa obra contém gatilhos" - se converte em medida crítica qualitativa onde "compor uma obra cheia de gatilhos" implica demérito.

A envergadura dessa questão certamente não poderia ser alcançada aqui, mas é importante evidenciar que tanto em Peso Bruto quanto em Ensaio sobre a retórica e como expectativa em T.R.A. reside a escolha de abordar, saturar e subverter tais situações compreendidas como gatilho o que implica uma recusa em render-se a uma retórica de auto-ajuda pautada na leveza da abordagem, que simultaneamente tira o debate do contexto social que implica e deixa palatável tópicos que - no debate como vem aqui sendo proposto - devem gerar desconforto. O imperativo de mobilizar estéticas do desconforto não implica em retirar avisos de possíveis gatilhos à plateias sensíveis, mas entende que se, como proposto anteriormente, não há o que ser curado pois não há doença e sim um protocolo de adoecimento de subjetividades marcadas pela diferença, a violência deste protocolo deve ser devolvida a quem o concebe.

O segundo aspecto é deste decorrente e articula uma possível pertinência da compreensão de cura no vocabulário das artistas que aqui escrevem. A recusa do pressuposto de adoecimento individual compreende que a doença não habita as corpas gordas, mas o tecido social que procura responsabilizá-las por 
não serem acolhidas. Há aí uma ferida social, cicatriz aberta pela qual se quer que a gordura vaze e desapareça. Há uma dualidade nessa compreensão de ferida social que é trauma para as corpas gordas: retirando-se do convívio, assujeitando-se a exclusão, permitindo que a cicatriz se feche com a queloide mais discreta possível a corpa gorda se protege das violências físicas e simbólicas que pode vir a sofrer mas como moeda de troca violenta-se. Como forma curativa da ferida social talvez caiba a gordura a função alquímica de converter-se em unguento e devolver a violência que the foi depositada: a cura dessa ferida é menos feita a base de pontos e gaze esterilizada e mais a partir de erva macerada em gordura aplicada junto de encantamentos,

Na mesa Narrativas anti-ajuda sucedida de modo online no 28ㅇ Festival Mix Brasil de Cultura e Diversidade (2020) o performer, poeta e crítico Francisco Mallmann teceu reflexões sobre a noção de cura no que concerne a ocupação dos espaços públicos por pessoas LGBTQIAP+ que são aqui pertinentes

[...] lembro de sentir o quão insuportável a minha presença era por esse desencaixe, por essa dissonância, por essa construção completamente distante de qualquer marcador normativo [...] esse grande espanto não é meu e carregar isso é uma violência que eu me auto imponho. Então eu quero devolver. Uma vez que eu não consigo ser compreendido por um campo normativo e cis-hetero-compulsório eu quero ser pesadelo na mente dessa gente. Se eu não puder ser sentença compreensível, se cognitivamente eles não puderem me formular que eu seja ruído. Mas que eu seja um ruído ensurdecedor. E eu acho que isso só é feito coletivamente, sabe? [..] No interior disso reside essa nossa potência de multidão, uma multidão dissonante (Mallman,2020, s.p., grifo nosso).

A fala de Mallmann é potente pois, na medida em que propõe converter a presença do corpo abjetizado em "ruído ensurdecedor", corrobora com a proposta de engraxar a queloide do trauma com a gordura de nossas presenças de modo a perturbar o sistema que persiste em adoecer nossas corpas, devolvendo espanto e violência por meio do engajamento na construção de um nós, uma nosotras ${ }^{11}$, dissonante, enfeitiçado, colossal.

${ }^{11}$ Se utiliza aqui o espanhol por ser a única língua onde a variação de gênero na primeira pessoa do plural é possível. 
Para finalizar esse texto retomamos os gestos banais, sensuais e oníricos para criar um espaço ficcional em T.R.A., de vislumbres de articulações possíveis entre as questões das corpas gordas, bichas e pesadas. Das lembranças disparadoras de novos começos, para a imaginação de um futuro incerto. Das dúvidas sobre o desejoso encontro presencial para as fabulações da gordura que ocupa cada vez mais espaços. Das alegorias construídas pelo excesso de zelo para as monstruosidades que se tornam irreconhecivelmente seguras. Do mosaico coreográfico que pinça detalhes de flacidez, gordura, estrias, celulites, bochechas grandes e peitões para a dança dos excessos, sobras, vazamentos e expansões. Do lip sync pop e precário para a diva de todo dia.

Um gesto inédito: fabular uma dramaturgia para a ficção do futuro

O ponto de encontro para o início da performance é em frente a um prédio de arquitetura imponente, acontecimento de cimento e tinta recortando céu, mar e asfalto, monolito de urbanidade, sólidos_carregados de história, imperturbáveis. De repente quem nas redondezas aguardava percebe que algo já se desenrolava. As frestas de janelas e portas vazam: uma substância branca se insinua pelos espaços estreitos até se derramar por sobre a madeira e vidro cobrindo-os. A substância parece ser gordura pressionando as barreiras que a contém. As dobradiças rangem, os vidros estalam e por fim um estouro anuncia o vazamento colossal de gordura que se derrama. É como se rebanhos, revoadas e cardumes inteiros dos animais a que pertencem estivessem se conjurando. O prédio se converte em um penetrável e após breve silêncio se ouve uma espécie de cantarolar sobreposto a uma percussão inconstante. As vozes parecem estar se aproximando e produzem algo que lembra um grito de guerra, um coral de bêbados, uma trupe de carpideiras, uma roda de chapados em meio a uma crise riso se sobrepondo e se revezando. Olhando para direção de onde as vozes vêm se vê dois pares de pernas deslocando suas respectivas corpas soterradas de acessórios. Não se vê pele, cabelo, unha, dente, barba, pelo, olho, mas sim 
cangas, máscaras, véus, chapéus, óculos, saco de lixo, bandeira, cadeira de praia, guarda sol e guarda chuva, isopor de bebida, borrifador. As corpas são grandes, imensas com suas extensões e empilhamentos. Adentram o buraco aberto pela banha. Correm até se golpearem contra a primeira parede em seu caminho, caem e ficam paradas. Quem estava ali para assistir também adentra o portal ainda escorregadio de gordura. De modo lento, quase imperceptível, dois focos de luz retangulares iluminam as duas corpas do topo da cabeça até a altura do final do osso externo. Essa imagem dura um tempo, e a luz natural diminui porque o sol se põe e janelas são fechadas. Sem mover sua parte inferior as duas corpas iniciam uma movimentação de torso, braços e cabeças iluminadas que não se pode precisar se é aleatória ou coreografada, mas, por vezes cada corpa parece ocupar o espaço negativo deixado pela outra, como duas peças de lego se aproximando. As corpas retiram as camadas de tecido, plástico e metal que the cobrem. Quando tiram as cangas e sapatos que thes cobrem da cintura para baixo os recortes se dissolvem. Quando estão apenas com o que aparenta ser roupa de baixo tiram do amontoado que tinham a si acoplados um recipiente de álcool em gel com o qual se limpam: mãos, pés, quaisquer partes que tenham tocado o chão. Limpam o rosto e usam o álcool em gel como gel de cabelo deixando o rosto em evidência. Uma das corpas revira e ordena a montanha ruinosa que delas se despregou. A outra rasga a roupa que veste em pequenos pedaços de pano que utiliza para limpar chão, paredes e objetos, criando um espaço cênico, quando termina sua tarefa higienizadora está nua e começa uma lenta descida ao solo enquanto a outra corpa se veste com uma segunda pele furta-cor escura e brilhante. Quando termina de se vestir, ocupa-se de vestir a outra corpa inerte no chão. Novamente tampadas as corpas se convertem em uma mancha que se move pelo espaço escuro como se o próprio espaço, chão e parede, estivessem se convulsionando e formando imagens antropomorfas que lembram obras clássicas que representam nudez em telas e esculturas. Quando as corpas finalmente se separam realizam uma série sutil de movimentos, quase imperceptíveis, como se fossem contidas por sua peleparede. Os gestos crescem, intensificam e avolumam conforme uma conversa verbal também se intensifica entre as vozes das corpas oriunda: é uma conversa 
na qual ninguém pára de falar, as vozes se sobrepõem e por vezes falam a mesma coisa, quando isso sucede retiram do espólio organizado dos escombros grandes bandeiras e amplas faixas que carregam as mesmas palavras ouvidas. Em um determinado momento a bandeira que se mostra ostenta as palavras "WE BELONG TOGETHER". Em silêncio essa bandeira é balançada até que se ouvem os acordes da canção homônima cantada por Mariah Carey. Sua voz jamais entra na melodia. Uma súbita iluminação em uma das paredes revela um vídeo de karaokê onde as letras da canção aparecem. A música trava e recomeça ao chegar na entrada vocal, até que uma das corpas mostra a boca e começa a cantar. Uma playlist é mostrada e as corpas se revezam entre cantar a música e dublar a versão do karaokê. Enquanto cantam as corpas se aproximam do público e persuadem a participar das próximas escolhas e performances, cadeiras de praia são abertas, ventiladores ligados para esvoaçar cangas e cabelos, os isopores saem das ruínas e revelam-se cheios de cerveja. Festa.

\section{Referências}

AUSTIN, John Langshaw. Quando dizer é fazer. palavras e ação. Porto Alegre: Artes Médicas, 1990.

BENJAMIN, Walter. Sobre o conceito da História. In: Magia e técnica, arte e política: ensaios sobre literatura e história da cultura 3a Ed. Tradução: Sérgio Paulo Rouanet. São Paulo: Editora Brasiliense, 1987.

BUTLER, Judith. Problemas de gênero: feminismo e subversão da identidade. Rio de Janeiro: Civilização Brasileira, 2015.

DO CARMO, Anderson e BELCHIOR SANTOS, Jussara. Ter corpo e ser corpo: percurso para uma dança da disponibilidade. [s.l.] In: Revista Carbono, 2013. Disponível em: http://revistacarbono.com/artigos/05ter-corpo-e-ser-corpocena11/. Acesso em: 30 nov. 2020.

FOUCAULT, Michel. Michel Foucault, uma entrevista: sexo, poder e a política e a identidade. In: Revista Verve: São Paulo, 1997.

HALBERSTAM, Jack. A arte queer do fracasso. Recife: Companhia Editora de Pernambuco, 2020. 
HALPERIN, David. San Foucault. Para una hagiografia gay. Buenos Aires: El cuenco de prata, 2007

HARTMAN, Saidiya. Scenes of subjection: Terror, Slavery, and Sel-Making in Nineteenth Century America. Oxford: Oxford University Press, 1997

LIMA, Carlos Henrique Lucas. Linguagens pajubeyras: re(ex)sistência cultural e subversão da heteronormatividade. Salvador: Editora Devires, 2017.

LIPOVETSKY, Gilles. Da leveza: rumo a uma civilização sem peso. Tradução: Idalina Lopes. Barueri: Manole, 2016.

MALLMANN, Francisco. Haverá festa com o que restar. Bragança Paulista: Editora Urutau, 2018.

MALLMANN, Francisco. Narrativas anti-ajuda. disponível em https://www.youtube.com/watch?v=Aq-KeNM1GYc\&t=2092s. Acesso em: 14 jan. 2021.

MOMBAÇA, Jota. Rumo a uma redistribuição desobediente de gênero e anticolonial da violência! Oficina de Imaginação Política. São Paulo: Fundação Bienal de São Paulo, 2016. Disponível em:

https://issuu.com/amilcarpacker/docs/rumo_a_uma_redistribuic_a_o_da_vi. Acesso em: 14 jan. 2020.

PASHALL, Jules. thank god i'm fat. gifts from the underbelly. Johnson, Don (Org.). Diverse bodies, diverse practices: toward an inclusive somatics. Berkeley, California: North Atlantic Books, 2018.

SCOTT, James C. Weapons of the weak: everiday forms of peasent resistence. New heaven e London: Yale University Press, 1987.

Recebido em: 15/01/2021

Aprovado em: 19/04/2021 